tại bệnh viện thông qua mức độ nặng của ngộ độc.

Tương tự, tổn thương thương thận mức độ 1 có số ngày nằm viện trung bình thấp nhất ( 4 ngày), mức độ 2 ( 4,5 ngày), mức độ 3 ( 8 ngày) với $\mathrm{p}<0,05$. Tỉ lệ tử vong cao nhất mức độ 2 $(57,1 \%)$ mức độ $1(29,1 \%)$, mức độ $3(20 \%)$, $\mathrm{p}<0,05$. Tổn thương thận trong quá trình điều trị càng nặng thì ngày nằm viện càng dài. Kết quả nghiên cứu của Negi $S$. và cộng sự về đặc điểm dịch tễ tổn thương thận cấp nói chung thì mức độ tổn thương thận có liên quan với tỉ lệ tử vong, ngày nằm viện và chỉ định điều trị thay thế thận [4]. Khác với Negi S. tỉ lệ tử vong trong nghiên cứu của tôi ít liên quan với độ nặng tổn thương thận, có thể do đặc điểm nhóm bệnh nhân nghiền cứu là ngộ độc khác với nghiên cứu của Negi S. nghiên cứu bệnh nhân nằm viện có tổn thương thận nói chung.

Theo mức độ nặng của ngộ độc (PSS) nhóm bệnh nhân có triệu chứng ngộ độc nặng có tỉ lệ tử vong $54,6 \%$ cao hơn tỉ lệ tử vong nhóm ngố độc mức độ trung bình 40,9\% và mức độ nhe tử vong $4,6 \%(p<0,05)$. Nêu độ nặng tổn thương thận không có mối liên quan với tỉ lệ tử vong thì ở đây mức độ nặng của ngộ độc có liên quan với tỉ lệ tử vong. Bệnh nhân tử vong do tác động trực tiếp của chất độc lên chức phận sống (ngộ độc paraquat gây xớ hóa phổi, tổn thương thần kinh trung ương trong ngộ độc methanol, suy đa tạng do ngộ độc ma túy đá...), tử vong cũng có thể do biến chứng viêm phổi, nhiểm khuẩn huyêt, rối loạn đông máu trong điều trị những ngộ độc nặng nằm viện thở máy kéo dài.

Nhóm bệnh nhân sống có tỉ lệ hồi phục thận $(72,5 \%)$ cao hơn nhóm tử vong $(31,8 \%)$, $\mathrm{p}<0,05$. Kết quả này cũng tương tự nghiên cứu của Singbartl K. và J.A. Kellum chỉ ra trong nghiên cứu tổn thương thận cấp ở bệnh nhân nặng, kết cục ở bệnh nhân có tổn thương thận cấp phụ thuộc vào bệnh lí nền, mức độ nặng và thời gian tổn thương thận, tình trạng nền của bênh nhân [6].

\section{KẾT LUÂN}

Đa số bệnh nhân $(60,3 \%)$ có tổn thương thận nặng lên trong quá trình điều trị, đặc biệt là các bệnh nhân chưa có tổn thương thận tại thời điểm nhập viện. $60,3 \%$ bệnh nhân có hồi phục chức năng thận khi ra viện, trong đó tỉ lệ hồi phục cao nhất là nhóm tổn thương thận mức độ 1 khi nhập viện. Ngộ độc càng nặng (theo thang điểm PSS) thì tỉ lệ tổn thương thận càng nặng. Bệnh nhân sống có tỉ lệ thận hồi phục cao hơn so với nhóm tử vong.

Tỉ lệ tử vong của bệnh nhân ngộ độc cấp có tổn thương thận cấp là 30,1\%.

\section{TÀI LIÊU THAM KHẢO}

1. Nguyễn Thị Dụ. Định hướng chung chẩn đoán và xứ trí ngộ độc cấp. Tư vấn chẩn đoán và xử trí nhanh ngộ độ́c câp. Nhà xuất bản Y học; 2004.

2. De Mendonça A, Vincent J-L, Suter P. Acute renal failure in the ICU: risk factors and outcome evaluated by the SOFA score. Intensive Care Medicine. 2000;26(7):915-921.

3. Kellum JA, Lamerie N, Aspelin P. KDIGO Clinical practice guidline for acute kidney injury. Kidney internatinal supplement. 2012:1-138.

4. Negi S, Koreeda D, Kobayashi S. Acute kidney injury: Epidemiology, outcomes, complications, and therapeutic strategies. Seminars in dialysis. 2018;31(5):519-527.

5. Persson HE, Sjoberg GK, Hainers JA, Pronczuk de Garbino J. Poisoning severity score. Grading of acute poisoning. J Toxicol Clin Toxicol. 1998;36(3):205-213.

6. Singbartl $K$, Kellum JA. AKI in the ICU: definition, epidemiology, risk stratification, and outcomes. Kidney international. 2012;81(9):819-825.

7. Thadhani R, Pascual M, Bonventre jV. Acute renal failure. The New England journal of medicine. 1996;334(22):1448-1460.

\title{
KẾT QUẢ ĐÎ̂̀U TRI PHẪU THUÂ̂T BẮC CẦU ĐộNG MẠCH TRONG VÀ NGOÀI SỌ TRONG PHÌNH ĐộNG MẠCH NÃO PHỨC TẠP
}

\section{TÓM TẮT}

\footnotetext{
*Bệnh viện Việt Đức

Chịu trách nhiệm chính: Ngô Mạnh Hùng

Email: ngomanhhung2000@gmail.com

Ngày nhận bài: 5.01.2021

Ngày phản biện khoa học: 3.3.2021

Ngày duyệt bài: 16.3.2021
}

\section{Ngô Mạnh Hùng*}

Mục tiêu: (1) mô tả các phương pháp điều trị phẫu thuật phình động mạch não phức tạp; (2) đánh giá kết quả điều trị phình động mạch não phức tạp và khổng lồ. Đối tượng và phướng pháp nghiên cứu: Nghiến cứu hồi cứu 17 bệnh nhân đã được điều trị phẫu thuật bắc cầu động mạch trong và ngoài sọ trong điều trị phình động mach não khổng lồ tại bệnh viện Việt Đức. Kết quả: tuổi trung bình: 37,39 $\pm 12,67$; có $58,83 \%$ nữ; các triệu chứng bao gồm: đau đầu, vắng ý thức, thất ngôn, yếu liệt vạn động, co 
giật; kích thước trung bình của phình mạch: $30,1 \pm 15,2 \mathrm{~mm} ; 58,83 \%$ phình hình túi; các vị trí của túi phình: động mạch cảnh trong đoạn ngoài sọ, trong so và động mach não giữa. Phẫu thuật bắc câuu lưu lượng cao $(64,71 \%)$, lưu lượng thấp $(35,29 \%)$. $94,12 \%$ số bệnh nhân có điểm mRS $\leq 2$ khi khám lại. Kết luận: phẫu thuật bắc câu động mạch trong và ngoài sọ là một lựa chọn phù hợp và có hiệu quả trong điêu trị các phình khổng lồ, phức tạp động mạch não.

Tư khoá: phình động mạch nã̃o; phình động mạch não khổng lồ/phức tạp; phẫu thuật; bắc cầu động mạch não trong và ngoài sọ

\section{SUMMARY \\ THE RESULTS OF EXTRACRANIAL- INTRACRANIAL BYPASS SURGERY FOR COMPLEX/GIANT CEREBRAL ANEURYSMS}

Objectives: (1) Describe the methods for treating complex/giant cerebral aneurysms; (2) assessment of surgical treatment of complex/giant cerebral aneurysms. Patients and methods: a retrospective study with 17 patients who were surgically treated by extracranial-intracranial bypass surgery at Viet-duc hospital. Results: mean age: $37.39 \pm 12.67$; female (58.83\%); signs and symptoms: headache, transient ischemia attack, aphasia, hemiparesis, and seizures. Location of aneurysms, including extracranial and intracranial internal carotid artery, and middle cerebral artery. Bypass surgeries composed high flow bypass $(64.71 \%)$, and low-flow bypass $(35.29 \%)$. At the follow-up time, there were $94.12 \%$ of patients had modified Rankin scale more than 2. Conclusion: Extracranial-intracranial bypass surgery was the usefulness and effective method.

Keywords: cerebral aneurysms, giant/complex cerebral aneurysms, surgery; extracranial-intracranial bypass surgery

\section{I. ĐĂT VẤN ĐỀ}

Phình động mạch nội so lớn và khổng lồ được định nghĩa là các túi phình có kích thước từ 18$24 \mathrm{~mm}$ và trên $24 \mathrm{~mm}$, tương ứng [1]. Phình động mạch não phức tạp bao gồm những túi phình động mạch não khổng lồ; các phình động mach não chứa đông mach mang, các nhánh xiển lớn hay có cấu trúc phức tạp [2]. Phình động mạch não khổng lồ chiếm khoảng $5 \%$ tổng số phình động mạch não nội sọ, có tiến triển tự nhiên rất phức tạp và kết quá tồi nếu không được điều trị phù hợp [3]. Các phương pháp điều trị phình động mạch não khổng lî̀ và phức tạp bao gồm điều trị nội khoa, can thiệp nội mạch và phẫu thuật. Mặc dù điêu trị can thiệp nội mạch ngày càng phổ biến trong điều trị phình động mạch não nói chung và phình động mạch khổng lồ nói riêng, song bệnh lý này vẫn là một thách thức [4]. Trong thực hành lâm sàng, ở nước ta, do cản trở về chi phí, khiến cho trong nhiều trường hợp bệnh nhân phình động mạch não khổng lồ, phẫu thuật trở thành lựa chọn duy nhất. Chúng tôi tiến hành nghiên cứu điều trị phẫu thuật bắc cầu động mạch trong và ngoài sọ trong bệnh lý phình động mạch não phức tạp với mục đích: (1) mô tả các phương pháp điều tri phẫu thuật phinh động mạch não phức tạp, và (2) đánh giá kết quả điều trị phinh động mạch não phức tạp và không lồ.

\section{II. ĐỐI TƯỢNG VÀ PHƯƠ'NG PHÁP NGHIÊN CỨU}

Trong thời gian từ 1.2016 đến 12.2020 đã có 17 bệnh nhân được chẩn đoán và điều trị phẫu thuật phình động mach não phức tạp/khổng lồ tại trung tâm phẫu thuật thần kinh, bệnh viện Việt Đức.

\section{- Tiêu chuân lựa chọn}

o Bệnh nhân được chẩn đoán phình động mạch não khổng lồ/phức tạp

o Được điều trị phẫu thuật bắc cầu động mạch trong và ngoài sọ

- Tham gia đầy đủ quá trình theo dõi sau mổ

o Có đầy đủ hồ sơ, phim chụp và các thông tin y khoa

\section{- Tiêu chuẩn loại trừ}

o Bệnh nhân không có ít nhất 1 trong các tiêu chuẩn lựa chọn ở trên

Phương pháp nghiên cứu: Mô tả, hồi cứu.

Các biến số nghiên cứu: tuối, giới, triệu chứng lâm sàng, chẩn đoán hình ảnh, kết quả test chẹn bóng động mạch cảnh trong (ballon occlusion test:BOT); phương pháp phẩu thuật, phương pháp điều trị, kết quả điêu trị theo thang điểm Rakin cải tiến (mRS).

Số liệu được thu thập và xử lý theo một mẫu bệnh án thống nhất

\section{KẾT QUẢ NGHIÊN CỨU}

Bảng 1. Đặc điểm chung, triệu chứng lâm sàng của nhóm bệnh nhân nghiên cứu

\begin{tabular}{|c|c|c|}
\hline \multicolumn{2}{|c|}{ Đặc điếm chung } & Số lượng (\%) \\
\hline \multicolumn{2}{|c|}{ Tuổi } & $\begin{array}{c}37,59 \pm 12,67 \\
\text { Thay đổi }: 21-62\end{array}$ \\
\hline \multirow{2}{*}{ Giới } & Nam & $7(41,17)$ \\
\cline { 2 - 3 } & Nữ & $10(58,83)$ \\
\hline \multirow{4}{*}{$\begin{array}{c}\text { Triệu } \\
\text { chứng lâm } \\
\text { sàng }\end{array}$} & Đau đầu & $15(88,23)$ \\
\cline { 2 - 3 } & Cơn vắng ý thức & $8(47,05)$ \\
\cline { 2 - 3 } & Thất ngôn & $3(17,64)$ \\
\cline { 2 - 3 } & Yếu/liệt vận động & $5(29,41)$ \\
\cline { 2 - 3 } & Sụp mi & $2(11,75)$ \\
\cline { 2 - 3 } & $\begin{array}{c}\text { Giảm cảm giác nưa } \\
\text { người }\end{array}$ & $4(23,53)$ \\
\cline { 2 - 3 } & Co giật & $4(23,53)$ \\
\hline
\end{tabular}

Tuối trung bình trong nhóm nghiên cứu là 37,59; đau đầu là triệu chứng thường gặp nhất. 
Ti lệ nam và nữ tương đương, không có sự khác biệt có ý nghĩa thống kê $(p>0,05)$

Bảng 2. Đặc điểm hình ảnh chẩn đoán túi phinh động mạch não

\begin{tabular}{|c|c|c|c|}
\hline Đặc điểm & & \begin{tabular}{|c|} 
Số lượng \\
$(\%)$
\end{tabular} & $\begin{array}{c}\text { Thay } \\
\text { đổi }\end{array}$ \\
\hline $\begin{array}{l}\text { Kích thước } \\
\text { túi phình } \\
\text { (mm) }\end{array}$ & & $30,1 \pm 15,2$ & $21-39$ \\
\hline \multirow{2}{*}{$\begin{array}{l}\text { Dạng túi } \\
\text { phình }\end{array}$} & Hình túi & $10(58,83)$ & \\
\hline & \begin{tabular}{|l|} 
Hình thoi \\
\end{tabular} & $7(41,17)$ & \\
\hline \multirow{3}{*}{$\begin{array}{l}\text { Vị trí phình } \\
\text { mạch }\end{array}$} & $\begin{array}{l}\text { Động mạch cảnh } \\
\text { trong ngoài sọ }\end{array}$ & $2(11,76)$ & \\
\hline & $\begin{array}{l}\text { Động mạch cảnh } \\
\text { trong nội sọ }\end{array}$ & $11(64,71)$ & \\
\hline & $\begin{array}{c}\text { Động mach não } \\
\text { giữa }\end{array}$ & $4(23,53)$ & \\
\hline \multirow{2}{*}{$\begin{array}{l}\text { Đặc điểm } \\
\text { của túi } \\
\text { phình }\end{array}$} & $\begin{array}{c}\text { Không có mạch } \\
\text { xiên }\end{array}$ & $14(82,36)$ & \\
\hline & Có mạch xiên & $3(17,64)$ & \\
\hline \multirow[t]{2}{*}{$\begin{array}{c}\text { Số lượng túi } \\
\text { phình }\end{array}$} & 1 túi & $14(82,36)$ & \\
\hline & Đa túi phình & $3(17,64)$ & \\
\hline \multirow{2}{*}{$\begin{array}{l}\text { Tình trang } \\
\text { phình khi } \\
\text { điều trị }\end{array}$} & Đã võ & $2(11,76)$ & \\
\hline & Chưa võ & $15(88,24)$ & \\
\hline
\end{tabular}

Kích thước của phình động mạch thay đối từ 21-39 mm. Các phình từ 18-24mm được gọi là phình mạch lớn, nhưng trong nhóm nghiên cứu các phình này có các nhánh xiên lớn đi ra, vì vậy chúng được xếp vào loại túi phình phức tạp, có chung phương pháp xử lý giống như túi phình khổng lî̀.

Có $17,64 \%$ số trường hợp có nhiều hơn 2 phình đông mạch não ở cùng một bênh nhân, trong đó có 2 bệnh nhân có các phình ở cùng một bên; và 1 bệnh nhân có phình ở bên đối diện.

Bảng 3. Phương pháp can thiệp, điều trị phẫu thuật

\begin{tabular}{|c|c|c|}
\hline \multicolumn{2}{|c|}{ Biến số nghiên cứu } & $\begin{array}{c}\text { Số lượng } \\
(\%)\end{array}$ \\
\hline \multirow{2}{*}{$\begin{array}{c}\text { Kết quả của } \\
\text { BOT }\end{array}$} & Dương tính & $13(76,47)$ \\
\cline { 2 - 3 } $\begin{array}{c}\text { Phương } \\
\text { pháp phầu } \\
\text { thuật bắc } \\
\text { cầu }\end{array}$ & $\begin{array}{c}\text { Dòng chảy } \\
\text { (high-flow) }\end{array}$ & $4(23,53)$ \\
\cline { 2 - 3 } & $\begin{array}{c}\text { Dòng chảy thấp } \\
\text { (low-flow) }\end{array}$ & $11(64,71)$ \\
\hline \multirow{2}{*}{$\begin{array}{c}\text { Phương } \\
\text { pháp can } \\
\text { thiêpp túi } \\
\text { phình }\end{array}$} & Túi phình tự tắc & $1(5,29)$ \\
\cline { 2 - 3 } & Cắt bỏ túi phình & $2(11,76)$ \\
\cline { 2 - 3 } & $\begin{array}{c}\text { Kẹp tạo hình túi } \\
\text { phình }\end{array}$ & $3(17,64)$ \\
\cline { 2 - 3 } & Nút tắc túi phình & $8(47,05)$ \\
\cline { 2 - 3 } & Theo dôi & $3(17,64)$ \\
\hline
\end{tabular}

Phẫu thuật bắc cầu động mạch dòng chảy cao là dạng sử dụng mảnh ghép tĩnh mạch hiển đảo chiều, với tốc độ chảy qua mảnh ghép là 100-200ml/phút; trong khi đó lưu lượng thấp trong nghiên cứu của chúng tôi là cầu nối động mạch thái dương nông-động mạch não giữa (STA-MCA bypass) (20-70mi/phút)

Bảng 4. Kết quả khám lại bệnh nhân

\begin{tabular}{|c|c|c|}
\hline Điểm mRS & Số lượng & Tỉ lệ \% \\
\hline 0 & 4 & 23,53 \\
\hline 1 & 9 & 52,94 \\
\hline 2 & 3 & 17,64 \\
\hline 3 & 1 & 5,88 \\
\hline
\end{tabular}

\section{BÀN LUẬN}

Túi phình động mạch não là một trong những bệnh lý thách thức nhất trong chuyên ngành phẫu thuật mạch máu thần kinh, cả can thiệp nội mạch và phẫu thuật $[4,5]$. Tần suất xuất hiện của bệnh lý này là khoảng $5 \%[3]$. Tuổi trung bình trong nhóm nghiên cứu của chúng tôi

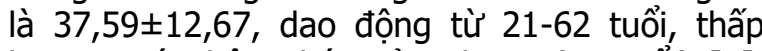
hơn so với thông báo của Sheen (57 tuối) [6], hay Chalouhi (57 tuổi) [7]. Có thể giải thích sự chênh lệch này là do số lượng bệnh nhân của chúng tổi còn thấp.

Tương tự với hầu hết các tác giả khác, tỉ lệ nữ trong nghiên cứu của chúng tôi có xu hướng cao hơn nam giới, bởi số lượng còn ít nên chưa thể tiến hành được các phương pháp thống kê. Có thể kể đến từ báo cáo của Sheen (81\%) [6], hay Chalouhi (77\%)[7].

Triệu chứng lâm sàng trong phình động mạch não khổng lồ và phức tạp đến từ hai nguyên nhân: tình trạng chèn ép của túi phình lên các cấu trúc não xung quanh và tình trạng huyết động của túi phình. Triệu chứng chính để chẩn đoán túi phình động mạch khổng lồ là hiệu ứng choán chố [3]. Các triệu chứng có thể gặp khác bao gồm: đau đầu, đột quỵ thiếu máu não thoáng qua và động kinh [8]

Nguy cơ võ của phình động mạch não tăng lên theo kích thước, nếu các túi phình dưới $7 \mathrm{~mm}$ được cho là nguy cơ thấp thì với kích thước trên $7 \mathrm{~mm}$ nguy cơ cao hơn có ý nghĩa thống kê. Với các phình động mạch não khổng lồ, nguy cơ võ cộng dồn trong 5 năm lên đến $40 \%$ [3].

Vị trí của túi phình cũng là một trong các yếu tố nguy cơ đối với tình trạng vỡ. Trong nghiên cứu của chúng tôi, toàn bộ các túi phình khổng lô/phức tạp đều nằm ở phần trước của đa giác Willis, lý do là bởi hầu hết các phình mạch của phần sau đa giác Willis đều có xu thế điều trị can thiệp nội mạch hoặc bảo tồn. 
Phương pháp xử lý túi phình có hay không có các mạch xiên cũng là một chủ đề có nhiều bàn luận trong y văn, giữa can thiệp nội mạch hay phẫu thuật. Ở đây, phẫu thuật bắc cầu động mạch não trong và ngoài sọ có nhiều ưu thế hơn so với can thiệp nội mạch, khi mà các mạch xiên khó kiểm soát hơn so với việc tái tạo tưới máu não. Nghiên cứu của chúng tôi quan tâm đến đặc điểm này để làm nổi bật ưu thế của phương pháp này so với can thiệp nội mạch, phần lớn phải hy sinh các nhánh xiên.

Đa túi phình động mạch não chiếm khoảng $20 \%$ tổng số các phình động mạch não nội sọ, và đây cũng là một trong các yếu tố cần phải được cân nhắc trong điều trị các túi phình động mạch não khổng lồ.

Test chẹn bóng tạm thời động mạch cảnh trong (BOT) được sử dụng thường quy trong đánh giá đặc điểm của các túi phình động mạch não khổng lî̀ và phức tạp, trong đó có thể phải làm tắc động mạch cảnh nuôi. Nhìn chung, đây là một thủ thuật an toàn, mặc dù đã có một số biến chứng được báo cáo, bao gồm lóc tách động mach, huyết khối động mạch, gây ra các giả phình.... Trong nhóm nghiên cứu của chúng tôi có 1 trường hợp có biến chứng khi tiến hành BOT. BOT được coi là dương tính khi bệnh nhân không có triệu chứng lâm sàng khi chẹn động mạch cảnh trong một bên trong 30 phút, và âm tính khi bệnh nhân có biểu hiện lâm sàng.

Với các bệnh nhân có BOT dương tính, chúng tôi giả định rằng tạo cầu nối động mạch dạng lưu lượng thấp (nối động mạch thái dương nôngđộng mạch não giữa: STA-MCA) là đủ tái tạo lưu lượng tưới máu não; trong khi đó, cầu nối lưu lượng cao (cầu nối giữa động mạch cảnh chung/động mạch cảnh ngoài- động mạch não giữa) sẽ được chỉ định cho các trường hợp BOT âm tính. Ngoài ra, vị trí của túi phình động mạch não cũng được cân nhắc trong lựa chọn loại cầu nối; với các phình ở động mạch cảnh trong cầu nối lưu lượng cao được ưu tiên sử dung và các phình động mạch não giữa là chẩn đoán được lựa chọn cho cầu nối lưu lượng thấp.

Bởi sự hạn chế về các trang thiết bị, chúng tôi đã không thể tiến hành xử lý túi phình động mạch ở tất cả các trường hợp. Chúng tôi thường tiển hành xử lý phình động mạch sau khi cầu nối đã được đảm bảo ở lần BOT tiếp theo. Trong nhóm nghiên cứu của chúng tôi, đã có 1 trường hợp túi phình tự tắc do giảm lưu lượng, 2 trường hợp cắt bỏ túi phình trực tiếp trong mổ; 8 trường hợp được nút tắc ở lần 2 và 3 trường hợp vẫn đang được theo dõi tiến triển của túi phình (đều là các túi phình nằm trong xoang tĩnh mạch hang, có nguy cơ vỡ thấp).

Đánh giá sau mổ, với thời gian theo dõi trung

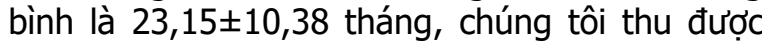
kết quả ở bảng 4. Gần $95 \%$ số trường hợp có điểm $m R S \leq 2$, chỉ có 1 trường hợp điểm $m R S=3$ (bênh nhân hôn mê trước mổ, túi phình có nhiều nhánh xiên).

Tiên lượng của phình động mạch não khổng lồ và phức tạp phụ thuộc vào tuổi, giới, tình trạng của túi phình cũng như phương pháp điều trị. Mục đích chính của điều trị là loai bỏ phình động mạch ra khỏi tuần hoàn trong khi bảo tồn được tưới máu não. Một trong các khó khăn khác của phình động mạch não khổng lồ là hiệu ứng choán chỗ của phình động mạch, nơi mà can thiệp mạch thường khó khăn hơn trong mục tiêu này.

\section{KẾT LUÂN}

Điều trị phình động mạch khổng lồ và phức tap còn nhiêu thách thức. Phẫu thuât bắc cầu động mạch trong và ngoài sọ là phương pháp điêu trị phù hợp, có hiệu quả và an toàn.

\section{TÀI LIÊU THAM KHẢO}

1. Sughrue, M.E., et al., Giant intracranial aneurysms: evolution of management in a contemporary surgical series. Neurosurgery, 2011. 69(6): p. 1261-70; discussion 1270-1.

2. Quinones-Hinojosa, A. and M.T. Lawton, In situ bypass in the management of complex intracranial aneurysms: technique application in 13 patients. Neurosurgery, 2008. 62(6 Suppl 3): p. 1442-9.

3. Lonjon, M., et al., Epidemiology, genetic, natural history and clinical presentation of giant cerebral aneurysms. Neurochirurgie, 2015. 61(6): p. 361-5.

4. Gonzalez, N.R., et al., Challenges in the endovascular treatment of giant intracranial aneurysms. Neurosurgery, 2008. 62(6 Suppl 3): p. 1324-35.

5. Sriamornrattanakul, K., et al., Surgical treatment of large and giant cavernous carotid aneurysms. Asian J Neurosurg, 2017. 12(3): p. 382-388.

6. Sheen, J.J., et al., Microsurgical treatment strategy for large and giant aneurysms of the internal carotid artery. Clin Neurol Neurosurg, 2019. 177: p. 54-62.

7. Chalouhi, $\mathbf{N}_{\text {., }}$ et al., Coiling of large and giant aneurysms: complications and long-term results of 334 cases. AJNR Am J Neuroradiol, 2014. 35(3): p. 546-52.

8. Zeeshan, Q., et al., Surgery for very large and giant intracranial aneurysms: Results and complications. Neurol India, 2018. 66(6): p. 1741-1757. 